\title{
A Qualitative Impact Evaluation of the First Love Yourself (FLY) Women's Support Group
}

\author{
Valerie Blackmon ${ }^{1}$, Chalenna Cassell ${ }^{2}$, Cathy G. McElderry ${ }^{3}$, Olawunmi Obisesan ${ }^{3}$ \\ ${ }^{1}$ University of Louisanna at Monroe, Monroe, LA, USA \\ ${ }^{2}$ Blackmon Consulting, Sikeston, MO, USA \\ ${ }^{3}$ Southeast Missouri State University, Cape Girardeau, MO, USA
}

\section{Article Info \\ Article history: \\ Received Feb 23, 2016 \\ Revised Mar 24, 2016 \\ Accepted Apr 27, 2016}

\section{Keyword:}

Empowerment

Family

Group therapy

Social support

Yalom's Therapeutic Factors

\begin{abstract}
Research has shown that social support groups not only have significant effects on the physical and mental health of individuals, but can also be used as predictors of health outcomes. It is, therefore, important that social workers and other public health professionals are aware of the social support groups that exist in communities so as to find ways to utilize these to meet health needs. The study aims to explore the First Love Yourself (FLY) group, an empowerment-based support group specifically designed to meet the needs of Healthy Start consumers, parents and consortium members. A qualitative analysis of the data gathered from this focus group study yielded several key themes. While participants described finding other community resources helpful, they reported having no other outlet for confidential selfexpression and connection to peers other than the FLY group. Group members also reported having improved self-esteem, relationships with their children, partners, and family, and ability to cope as a result of participation in the group. Participants further described gaining knowledge and learning skills that were helpful. This included learning parenting, communication, stress and anger management, budgeting, goal-setting and coping skills and techniques. Finally, qualitative analysis of the data gained from the focus group with participants and the group leader revealed the presence of all 11 curative factors described as Yalom's Therapeutic Factors. The primary areas for improvement noted by the group and its leader were related to the frequency of group meetings. Both audiences indicated that additional sessions would be beneficial.
\end{abstract}

Copyright (C) 2016 Institute of Advanced Engineering and Science. All rights reserved.

\section{Corresponding Author:}

Valerie Blackmon,

University of Louisanna at Monroe,

700 University Ave,

Monroe, LA 71209, USA

Email: Valerie@blackmonconsulting.org

\section{INTRODUCTION}

The roles of social support and psychosocial empowerment have been identified as a process to influence health and life outcomes [1]. Empowerment has been described as an essential part of change. People who have access to information about specific situations in which they find themselves and their environments are better informed on conditions that impact their lives and health, and better equipped to handle these situations when they occur [1]. A supportive social environment creates an atmosphere of mutual respect and trust, equipping individuals with what they need to be in control of their life and health [2].

The aim of this paper is to examine the overall impact of participation in the First Love Yourself (FLY) Women’s Support Group implemented by the Missouri Bootheel Regional Consortium, Inc. (MBRC). 
MBRC's FLY group was originally designed to be a 12-16 week monthly support group available to Healthy Start Consumers, parents and consortium members, aged 18 and above. Within the group, both didactic and experiential techniques are utilized to increase members ability to more effectively parent, communicate with others, prioritize and set goals, problem solve, make healthy decisions and cope with daily stressors. The group is also meant to empower women to better care for themselves and support one another. The group is led by a licensed doctoral level clinician who facilitates discussions and works collaboratively with group members to create monthly homework assignments aimed to meet established personal goals. The conceptual framework for this study was Yalom's curative factors. In a foundational work as it relates to the practice of group therapy, Yalom and Leszcz (2005) detail 11 group therapy factors, which are esteemed to have a curative effect when skillfully fostered in the group therapy process [3]. Research has validated the use of support groups to foster improved wellbeing [4],[5] and to fill gaps in access to services [6]. This study will assess the presence of Yalom's curative factors as a means of evaluating the success of the FLY group within a Black female population. Table 1 contains the names and definitions of Yalom's 11 curative factors.

Table 1. Yalom (2005) Therapeutic Factors

\begin{tabular}{|c|c|}
\hline Therapeutic Factors & Definition \\
\hline Instillation of Hope & $\begin{array}{l}\text { Process by which hope is inspired through observation of therapeutically } \\
\text { advanced group members. }\end{array}$ \\
\hline Universality & $\begin{array}{l}\text { Process by which group members feel less isolated in their pain as they } \\
\text { connect to others with similar experiences. }\end{array}$ \\
\hline Imparting of Information & $\begin{array}{l}\text { Psychoeducation is provided by group leaders, and experiential knowledge is } \\
\text { transmitted between group members. }\end{array}$ \\
\hline Altruism & $\begin{array}{l}\text { Clients learn that their contributions to the group are vital to the healing of } \\
\text { others. }\end{array}$ \\
\hline $\begin{array}{l}\text { Corrective recapitulation of the } \\
\text { primary family group }\end{array}$ & $\begin{array}{l}\text { The group is experienced as a familial unit allowing for healing of early } \\
\text { wounds and relearning of unhealthy patterns learned within one's family of } \\
\text { origin. }\end{array}$ \\
\hline Development of Socializing & Within group experiences communicating with one another and providing \\
\hline Techniques & interpersonal feedback allow for improved social skills outside of the group. \\
\hline Imitative Behavior & $\begin{array}{l}\text { Group members model the behavior of the group leader and other } \\
\text { therapeutically advanced members. }\end{array}$ \\
\hline Interpersonal Learning & $\begin{array}{l}\text { Healing takes place as group members form healthy supportive relationships } \\
\text { with others within the group. }\end{array}$ \\
\hline Group Cohesiveness & $\begin{array}{l}\text { Acceptance from others within the group fosters a sense of internal security, } \\
\text { trust, and belongingness. }\end{array}$ \\
\hline Catharsis & $\begin{array}{l}\text { The group process fosters the identification and healthy expression of } \\
\text { emotion. }\end{array}$ \\
\hline Existential Factors & $\begin{array}{l}\text { The group process allows members to explore their beliefs about the meaning } \\
\text { of life and their life roles. }\end{array}$ \\
\hline
\end{tabular}

\section{RESEARCH METHOD}

Qualitative data were collected using two approaches for this study: A focus group among participants and an in-depth interview with the clinician. The focus group was composed of five program participants. All participants live in the Bootheel region of Southeast Missouri and are MBRC consumers. Each participant had, at least, one child and reported being active in other components of the program offerings at MBRC. Focus group members reported that case manager interaction led to enrollment in the FLY group. Focus group participants were selected utilizing the convenience sampling technique whereby available FLY group attendees were asked to participate in the focus group. Participants were informed that while some verbatim responses would be recorded, all identifying information would remain confidential. A doctoral-level mental health clinician moderated the session utilizing a semi-structured approach whereby group members participated in a discussion revolving around a set of pre-established questions.These questions aimed to gather information about group members perspective of the strengths and weaknesses of the group as well as the impact participation has on their daily lives including goal achievement, sense of self, parenting, and family relationships. The moderator provided clarification of questions when needed and recorded handwritten verbatim responses and a synopsis of key responses provided by group members.

The in-depth interview with the group facilitator was conducted in a face-to-face setting during the same time as the focus group by a doctoral level researcher. Both the focus group and the interview were approximately 90 minutes in duration. The clinician was interviewed as the focus group was being conducted; therefore, the two groups did not have an opportunity to discuss the focus group questions until 
after the data had been collected. The results consist of a thematic analysis of the qualitative data. The Southeast Missouri State University’s Institutional Review Board approved the study.

\section{RESULTS AND ANALYSIS}

Focus group members were asked to describe their experiences relative to participating in the FLY group. As a whole group, members unanimously reported highly positive experiences both within the group as well as a positive change in their lives outside of the group as a result of group participation. As it relates to changes in their day to day life; group members reported feeling "more peaceful," that they "strive harder to...achieve" established goals, have "better [platonic and romantic] relationships", and are "better [at] parenting." As it relates to parenting, group members also reported being "more patient” with their children. For instance, three group members described learning to "take time to talk to" versus "yelling at" their children and having learned to "walk away" when especially angry and "come back" after calming down. Group members also described understanding the importance of modeling positive behavior as a result of group discussions and reported utilizing "time out" instead of "spanking." It should be noted that mothers expressed having more positive interactions with their children and having better outcomes when utilizing this method. Furthermore, group members discussed spending more quality time with their children after spending time exploring low- to no-cost family bonding activities within the group.

Participants shared how FLY group participation has positively impacted their sense of self. As a whole, group members described feeling "more confident.” One group member affirmed that attending the group "brings your self-esteem up" while another stated that "instead of doubting myself I feel like yes I can do this!” Participants attributed much of the group's success to the skill of the group facilitator with whom group members clearly demonstrated having a strong rapport. One group member stated, "she also taught us how to love our self because some of us had low self-esteem and [needed] to take time for ourselves." Group members also esteemed very positive characteristics to the group leader reporting that she "loves God," "listens and doesn't try to talk over you", shares in a way that increases "the trust factor", and that she will "cry with you too."

In addition to support from the group facilitator, the factor that seemed to be most esteemed was the level of support group members described receiving from one another. One FLY member stated "it's like we're all a big family"; while another voiced appreciating "having the support of someone pushing and believing in you." Another member stated having learned from the group that "even if you don't believe in yourself, there are always people that believe in you." Group members also shared how participating in the group helped them learn that "you can trust people" and reported that they felt comfortable and safe "talk[ing] about anything" within the group due to the established level of trust.

\subsection{Acquired Skills \& Knowledge}

Members of the focus group were asked to describe specific knowledge and skills that have been attained as a result of group participation. Group members reported that wide ranges of topics were discussed from budgeting to sexual relationships. As it relates to specific skills, group members reported learning specific stress and anger management techniques such as breathing training and yoga. Group members also voiced learning particular lessons which were helpful such as "can't nobody make you angry but yourself" and the importance of believing in oneself. In addition, group members discussed learning how to "set goals and achieve them" and to better "communicate" and "to think before you act." As it relates to setting goals, group members described working within the group to identify personal goals, create achievable steps for reaching goals, and choose monthly "homework assignments" designed to move them forward in achieving goals. Goals mentioned included obtaining a driver's license, earning one's General Educational Development (GED), participating in Substance Abuse Traffic Offender Program (SATOP) recovery classes, improving one's diet, improving relationships including parenting relationships, practicing budgeting, and finding a job.

\subsection{Barriers and Supporting Factors}

Given the numerous stressors, that group member's face in their daily lives, factors that may prevent or discourage group attendance were also assessed. Group members reported that the most significant barrier encountered revolved around having multiple roles and numerous responsibilities, which create a hectic schedule. Participants also reported that last minute transportation and child care issues were problematic. However, each group member stressed prioritizing the group as they reported finding it extremely helpful. One group member shared that she had missed her niece's first sports game in order to attend the group. Other members indicated that due to work or parenting related scheduling conflicts "we may be late, but we always come.” While childcare and parenting conflicts were cited as a barrier, group members reported 
finding it essential to have time for themselves. One member poignantly stated, "I like the fact that you can't bring kids with you...it forces you to relax [and] helps you think about yourself.”

Participants named several supporting factors, which contribute to their ability to attend group meetings. This included having transportation provided, child care assistance, reminder phone calls and letters, as well as a strong sense of connection to the group facilitator. Barriers to group member's initially joining the class were also discussed. Group members reported having been recruited by an MBRC case manager with whom they had an established relationship. They cited their overall positive experience with MBRC and trust in their case manager as factors, which contributed to their decision to join the group. They also named "wanting parenting help" and needing "a place to get support" as additional contributing factors. They expressed initial concern that participants noted would have prevented them from joining the group was a fear that "[their] business would get out there if there were others from the same community" in the group.

The fact that confidentiality is valued by all members was listed as a supporting factor in continued attendance. Group members did not list any additional factors that would prevent them from attending the group. Furthermore, participants reported that they did not have any constructive feedback to share other than wishing that the group was offered more than once per month. Another group member also shared that while the group as a whole "loves to have" new members, these members typically "don't stay" in the group. Members expressed wanting to expand the group to include others given that the group has been so instrumental in their lives.

\subsection{Clinician Perspective}

The licensed mental health clinician in charge of facilitating the group indicated that FLY is an open group in that members may join or leave at any time during the 12-week session. The clinical approach is one that focuses on the needs of the group rather than a being curriculum based. The clinician stated, "I want the group to be their own." She, however, indicated that she did present to group prepared with skill-based topics such as: problem-solving, communication, goal-setting, coping, budgeting, and anger management. She noted that goal setting and problem solving were a primary emphasis when a new session began and that this often changed based upon group needs. She indicated that often the group emerged into a process group as deeply-rooted emotions surface during the discussion. Due to the number of stressors faced by the group members and the frequency of group meetings, when core emotional distresses surfaced, the emotional needs were attended to as appropriate for the group setting. Often this meant the session becomes a psychological process group, largely because the group offers a "safe place" to openly self-disclose. It was noted that the members often hold one another accountable for goal achievement, honesty and peer support among members.

The clinician described measuring success in terms of goal achievement and the demonstration of emotional growth. Among the noteworthy successes noted by the clinician were: ability to identify and achieve a goal, changes in sense of confidence and self-worth, openly sharing within the group, and sense of self-efficacy. The major challenges noted were the long period between group meetings (usually 30 days) and the openness of the group relative to points of entry. Consequently, improvement for the group related to the frequency of meeting. The facilitator specifically noted that bi-monthly meetings would offer more opportunity to hold women accountable, capture more participants and maintain progress.

\section{DISCUSSION}

Each of Yalom's 11 therapeutic factors appeared to be present. Certain elements of these factors were discussed very concrete by group members. Catharsis and Universality were evident as group members and group leader discussed benefiting from having the group as a safe emotional outlet to talk with peers who had similar experiences [7]. Group cohesiveness and corrective recapitulation of the primary family were also very apparent as the group described feeling a familial bond with one another and having learned to trust others as a result of group interaction [8]. Imparting of Information was also evident as group members discussed learning specific skills that allow them to parent and cope more effectively. There were also signs of interpersonal learning and altruism as group members expressed how supportive others in the group were and shared the importance of holding one another accountable for completing homework assignments [7],[9].

Additionally, the development of socializing techniques was also demonstrated as group members discussed having improved platonic, romantic, and parenting relationship as a result of the group [8],[9]. Elements of the remaining factors may not have been discussed explicitly by group members but nonetheless were observed during data collection and noted during the clinician interview. For instance, Imitative Behavior was not explicitly discussed during the focus group but was apparent in the esteem group members had for their group leader who they ascribed qualities that they would like to demonstrate. The group leader also noted that members often demonstrate imitative behaviors when new group members arrive or in 
holding one another accountable. Furthermore, group members did not explicitly use the term hope; however, they did demonstrate having hope for the future by having engaged in future-oriented behavior (i.e. creating and working towards goals). Group members also demonstrated Existential Factors as they shared being more aware of their goals, roles as parents, and themselves as individuals. Thus, it appears that the FLY group, as implemented, fosters each of Yalow's corrective therapeutic factors.

\section{CONCLUSION}

The results of this qualitative data analysis suggest that each of the Yalom's corrective therapeutic factors appear to be appropriately fostered by the group process. As it relates to regional services, participants discussed finding other programs offered to be vital but reported having no other outlet for confidential selfexpression and connection to peers. Concerning the impact of group participation, members reported having improved self-esteem, relationships with their children, partners, family and ability to cope. Participants also described gaining knowledge and learning skills that were helpful, including learning parenting, communication, stress and anger management, budgeting, goal-setting and coping skills and techniques.

Group members reported having several barriers, which would either prevent them from attending groups or contribute to late attendance. However, they shared that MBRC has addressed many of these issues by providing child care assistance and transportation. The two unmet concerns raised by group members related to the low frequency of group sessions and difficulty retaining new group members. The same concerns were expressed by the group leader as well. It is suggested that ways to potentially expand the group is considered and possibilities for increasing the frequency of group meetings be explored.

\section{REFERENCES}

[1] Lord J. \& Hutchison P., “The process of empowerment: implications for theory and practice,” Canadian Journal of Community Mental Health, vol/issue: 12(1), pp. 5-22, 1993. Available from: http://www.johnlord.net/web_documents/process_of_empowerment.pdf.

[2] McMurray A. \& Clendon J., "Community health and wellness: primary health care in practice (5 ed.)," London, UK, 2015.

[3] Yalom I. \& Leszcz M., “The theory and practice of group psychotherapy (5th ed.),” New York, NY, 2005.

[4] Byrne C., et al., "Effects of mindfulness-based versus interpersonal process group intervention on psychological well-being with a clinical university population,” Journal of College Counseling, vol/issue: 16(3), pp. 213-227, 2013. Available from: http://dx.doi.org/10.1002/j.2161-1882.2013.00038.

[5] C. L. Marmarosh \& G. A. Tasca, “Adult attachment anxiety: Using group therapy to promote change,” Journal of Clinical Psychology, vol/issue: 69(11), pp. 1172-1182, 2013. doi:10.1002/jclp.22044.

[6] Diefenbeck C. A., et al., "Emergence of Yalom's therapeutic factors in a peer-led, asynchronous, online support group for family caregivers,” Issues in Mental Health Nursing, vol/issue: 35(1), pp. 21-32, 2014. Available from: http://dx.doi.org/10.3109/01612840.2013.836260.

[7] Kline W. B., “Interactive group counseling and therapy,” Upper Saddle River, New Jersey, 2003.

[8] Caruso R, et al., "Exploration of experiences in therapeutic groups for patients with severe mental illness: development of the Ferrara group experiences scale (FE- GES),” BMC Psychiatry [Internet]. Springer Science + Business Media, vol/issue: 13(1), pp. 242, 2013. Available from: http://dx.doi.org/10.1186/1471-244x-13-242.

[9] Marogna C. \& Caccamo F., "Analysis of the process in brief psychotherapy group: the role of therapeutic factors," ResPsy, PAGEPress Publications, vol/issue: 17(1), pp. 43, 2015. Available from: http://dx.doi.org/10.4081/ripppo.2014.161.

\section{BIOGRAPHIES OF AUTHORS}

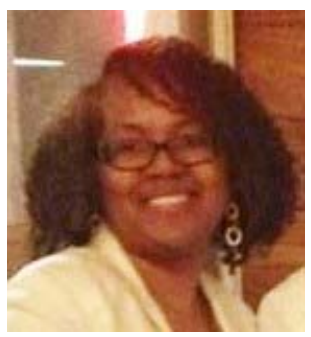

Valerie Blackmon is an experienced management consultant who specializes in organizational performance. She earned a Bachelor of Science with Double Majors in Accounting and Marketing Management in 1986 from Southeast Missouri State University. Later in 1997 she earned a Master of Science in Public Administration from Southeast Missouri State University; finally, in 2008 she earned a Doctor of Philosophy in Organization and Management, from the School of Business and Technology at Capella University. In addition, Dr. Blackmon has nearly three decades of progressive professional work experiences. Her career began in auditing and accounting in both the for-profit and not-for-profit industries. Her work experience includes 10 years in governmental; three as an internal auditor, two in a University setting and another five in financial management for a private not-for-profits. For the past fourteen years, she has worked as a management consultant with an emphasis on improving organizational performance. In this role, she provides executive coaching, strategic planning, program evaluation, research and data analysis, and several workshops and trainings for organizations. Dr. Blackmon is also an experienced higher education instructor. She has taught 
business classes in management and accounting both in live face-to-face settings and in an online environment. She is currently an adjunct for Argosy University and teaches management, strategic planning and non-profit management courses in their MBA and MPA programs and the University of Louisiana at Monroe where she teaches in the MPA program.

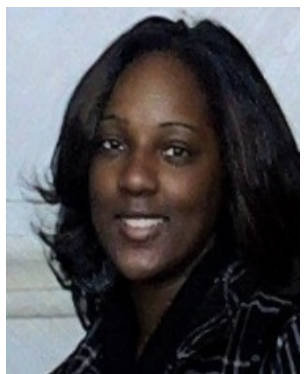

Chalenna Cassell is a clinical psychologist with specialized training in treating trauma related and dissociative disorders. Dr. Cassell earned a Doctorate in Clinical Psychology from the Georgia School of Professional Psychology and a Master of Community Counseling from Southeast Missouri State University. Dr. Cassell also completed her undergraduate degree at Southeast Missouri State University where she double majored in Psychology and Criminal Justice. She currently works as a consultant at Blackmon Consulting, LLC where she assists with grant writing and research. Her research interests include complex trauma, prolonged exposure to community violence, minority mental health and resiliency, and the generational impact of trauma, racism, and oppression.

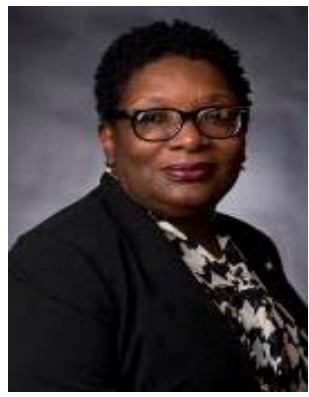

Cathy Gilbert McElderry is an associate professor and chair of the Department of Social Work at Southeast Missouri State University. Dr. McElderry earned her Ph.D. in Social Work from the University of Alabama. Dr. McElderry holds a Master of Social Work from Clark Atlanta University (formerly Atlanta University) and a Master of Public Health from the University of Alabama in Birmingham. Dr. McElderry is a licensed practitioner in a health and mental health practice. Dr. McElderry's research focuses on social determinants of health and well-being. She is particularly interested in advancing an understanding of the role of socioeconomic disparities in initiating, shaping, and contributing to problematic outcomes such as substance abuse, poverty, poor academic achievement, and other social issues. Dr. McElderry's scholarly activities extend to the investigation of women issues such as access to healthcare, HIV/AID, and gender-based violence. Dr. McElderry is a Deputy-Editor for the Journal of Gender, Information and Development in Africa.

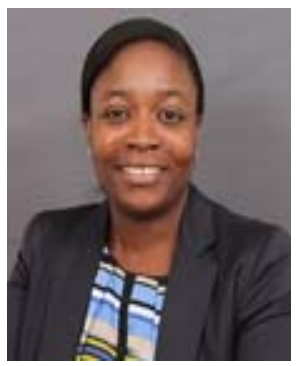

Olawunmi Obisesan is an adjunct faculty in the Department of Social Work at Southeast Missouri State University, Missouri, USA. Olawunmi holds several degrees including a PhD in Public Health (Epidemiology) from Walden University. She is currently completing another doctoral program in Health Education from A.T. Still University and an MPH program in Prevention Science from Emory University, Rollins School of Public Health. Olawunmi has worked with several hospitals and is currently the Coordinator for the Regional Arthritis Center (RAC) for 16 counties in Southeast Missouri. Under the RAC program, Olawunmi has implemented several CDC-funded evidence-based programs for the State of Missouri, including the Stanford University's Chronic Disease Self-Management Program (CDSMP). Olawunmi's research interests include issues that affect the health of vulnerable populations, especially immigrants. 